\title{
Designing a Genetic Algorithm to Solve an Integrated Model in Supply Chain Management Using Fuzzy Goal Programming Approach
}

\author{
M. Rostami N. K.i ${ }^{*}$, J. Razmi, and F. Jolai \\ Department of Industrial Engineering, College of Engineering, University of Tehran, Iran \\ \{jrazmi, marostamy, fjolai\} @ut.ac.ir
}

\begin{abstract}
Application of fuzzy goal programming and genetic algorithm is considered in this paper. We extend a multi-objective model for integrated inventory-production-distribution planning in supply chain (SC). We consider a supply chain network which consists of a manufacture, with multiple plants, multiple distribution centers (DCs), multiple retailers and multiple customers. The manufacturer produces several items. Decision maker's imprecise aspiration levels of goals are incorporated into model using fuzzy goal programming approach. Due to the complexity of problem in large size and in order to get a satisfactory near optimal solution with great speed, a new genetic algorithm is proposed to solve constrained problems. To show the efficiency of the used model and fuzzy goal programming approach and genetic algorithm for the collaborative inventory-production-distribution problem, computational experiments are performed on a hypothetically constructed case problem.
\end{abstract}

Keywords: fuzzy goal programming, supply chain management, genetic algorithm.

\section{Introduction}

Industries around the world are now all rushing the territory of globalization and specialization. Cooperating with good strategic partner is the sure way to tackle the potential problems arising from competition. Companies can achieve the optimum operating efficiency by working with other companies through communication and specialization which evolve a new type of relationship, the SC relationship, among these companies and further faster a new concept in management: the supply chain management (SCM). Production and distribution operations are the two most important operational functions in a SC. To achieve optimal operational performance in a SC, it is critical to integrate these two functions and plan them jointly in a coordinated way [[1],[9]]. Different aspects of integrated problems for different parts of supply chain have been considered in the literatures. Nozick and Turnquist [9] tried to integrate inventory, transportation and location functions of a supply chain. The proposed model has been confined to a single period, single echelon problem with no capacity constraint.

\footnotetext{
* Corresponding author.
} 
Some researchers have investigated fuzzy production planning problems in SC ([10], [1], [5]). Decision analysis in e-supply chain using fuzzy set approach mainly on the basis of fuzzy reasoning Petry nets has been considered by Gao et al [5]. The method proposed by Liang [8] aims at simultaneous minimization of total distribution costs and the total delivery time on the basis of fuzzy available supply, total budget, fuzzy forecast demand, and warehouse space. Chen et al. [4] suggested an approach to deriving the membership function of the fuzzy minimum total cost of the multi-period SC model with fuzzy parameters. The considered fuzzy production planning models and methods are mainly a single product type and separate production planning model without integration with distribution and inventory problems. Computational intelligence is widely used in economics and finance [Chen [3], Sheen [11], Zadro et al. [14]]. Torabi and Hassini [13] considered a supply chain master planning model consisting of multiple suppliers, one manufacturer and multiple distribution centers. They proposed a method to solve multiobjective linear programming (MOLP) models, named TH. Although many researchers have been devoted to solve production-distribution problems in SC environment, there is a few researches that integrates an aggregate inventory-production and distribution plan in a collaborative manner using fuzzy modeling approaches.

This paper contributes to the literature by presenting a multi objective model with resource constraints and lead times and considering a manufacturer with states which is near to real world rather than other models and using FGP approach for handling the collaborative inventory- production-distribution planning problems SC and presenting a new genetic algorithm approach for constrained problems. Evolutionary algorithms such as genetic algorithm were used to solve combinatorial problems. A Genetic algorithm (GA) based method has been used to develop an efficient solution algorithm by Tasan[12]. Fuzzy-Genetic approach has been proposed to aggregate production and distribution planning in supply chain management by Aliev et al [2]. Many challenges arise when the algorithm is applied to heavily constrained problems where feasible regions may be sparse or disconnected. This study proposes an approach to obtain solutions which are close to the feasible region.

\section{Mathematical Model}

\subsection{Indices}

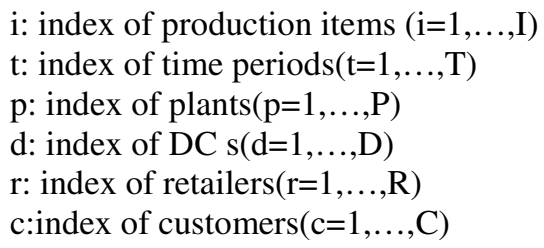

\subsection{Problem Assumptions}

The assumptions to model the problem are as follows:

1. It has been considered a manufacturer with p plants, $d$ distributors, $r$ retailers, and c customers

2. All of the decisions are made within multi-periods. 
3. Customers assign cost for backorder as a penalty for retailers.

4. There is transportation capacity constraint for all echelons.

5. Delivery due dates have been assigned by distributors.

\subsection{Parameters}

$\mathrm{CD}_{\text {irct }}$ : Amount of product $\mathrm{i}$ demanded by customer $\mathrm{c}$ from retailer $\mathrm{r}$ in period $\mathrm{t}$. $\mathrm{PCP}_{\mathrm{i}}$ : Unit production cost of product $\mathrm{i}$.

$S P M D_{i t}$ : Unit sales price for product i from manufacturer to DCs in period $t$. This included product cost, the cost of transportation, and ordering cost.

$S P D_{\text {idrt }}$ : Unit sales price for product i from $D C d$ to retailer $r$ in period $t$.

$\mathrm{TCPD}_{\text {ipdt }}$ : Unit transportation cost for product i from plant $\mathrm{p}$ to $\mathrm{DC} \mathrm{d}$ in period $\mathrm{t}$. DC pay it.

$\mathrm{HCF}_{\mathrm{ip}}$ : Unit inventory holding cost of final product $\mathrm{i}$ in plant $\mathrm{p}$.

$\mathrm{HCD}_{\text {id }}$ : Unit inventory holding cost of final product i in DC d.

FHCP $_{\text {ipt }}$ : Final product i warehouse capacity in plant $p$ in period $t$.

PHCP $_{\text {idt }}$ : Final product i warehouse capacity in DC $d$ in period $t$.

PHCR $_{\text {irt }}$ : Final product i warehouse capacity in retailer $r$ in period $t$.

$\mathrm{TFP}_{\mathrm{i}}$ : Unit processing time for final product $\mathrm{i}$.

$\mathrm{TDR}_{\mathrm{drt}}$ : Transportation capacity from $\mathrm{DC} d$ to retailer $r$ in period $t$.

DUEM $_{\text {ipdt }}$ : Delivery due date for product i from DC $d$ to manufacturer in period $t$. $\mathrm{TPD}_{\mathrm{pd}}$ : The time required to ship the products from plant $\mathrm{p}$ to $\mathrm{DC} d$.

$\mathrm{TCM}_{\mathrm{pdt}}$ : Transportation capacity from plant $\mathrm{p}$ to DC $\mathrm{d}$ in period $\mathrm{t}$.

\subsection{Decision Variables}

PTD $_{\text {idrt }}$ : Amount of product $i$ to be transported from DC $d$ to retailer $r$ in period $t$. $\mathrm{TRC}_{\text {irct }}$ : Amount of product $\mathrm{i}$ to be transported from retailer $\mathrm{r}$ to customer $\mathrm{c}$ in period $t$.

PTPD $_{\text {ipdt }}$ : Amount of product $i$ to be transported from plant $p$ to $D C d$ in period $t$.

$\mathrm{ID}_{\text {idt }}$ : Inventory of product $\mathrm{i}$ at the $\mathrm{DC} \mathrm{d}$ in period $\mathrm{t}$.

$I_{\text {irt }}$ : Inventory of final product $i$ in retailer $r$ in period $t$.

$\mathrm{PQ}_{\text {ipt }}$ : Production quantity of product $\mathrm{i}$ in plant $\mathrm{p}$ in period $\mathrm{t}$.

$\mathrm{BCR}_{\text {irct: }}$ : The amount of backorder of product $\mathrm{i}$ from retailer $r$ to customer $\mathrm{c}$ at the end of period $t$.

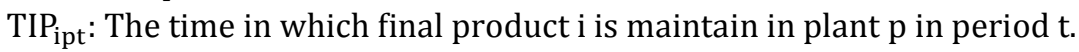

$\mathrm{FP}_{\mathrm{ipt}}$ : The amount of inventory of product $\mathrm{i}$ in plant $\mathrm{p}$ in period $\mathrm{t}$

\subsection{Objective Functions}

Manufacturer Profit :( Maximization)=sales revenue-total manufacturing cost total inventory types holding cost

$$
\begin{gathered}
=\sum_{\mathrm{i}} \sum_{\mathrm{p}} \sum_{\mathrm{d}} \sum_{\mathrm{t}}\left(\mathrm{SPMD}_{\mathrm{it}} * \mathrm{PTPD}_{\mathrm{ipdt}}\right)-\sum_{\mathrm{i}} \sum_{\mathrm{p}} \sum_{\mathrm{t}}\left(\mathrm{PCP}_{\mathrm{i}} * \mathrm{PQ}_{\mathrm{ipt}}\right) \\
-\sum_{\mathrm{i}} \sum_{\mathrm{p}} \sum_{\mathrm{t}}\left(\mathrm{HCF}_{\mathrm{ip}} * \mathrm{FP}_{\mathrm{ipt}}\right)
\end{gathered}
$$


inventory cost-total transportation cost

$$
\begin{aligned}
= & \sum_{\mathrm{i}} \sum_{\mathrm{r}} \sum_{\mathrm{t}}\left(\mathrm{SPD}_{\mathrm{idrt}} * \mathrm{PTD}_{\mathrm{idrt}}\right)-\sum_{\mathrm{i}} \sum_{\mathrm{p}} \sum_{\mathrm{t}}\left(\mathrm{SPMD}_{\mathrm{it}} * \mathrm{PTPD}_{\mathrm{ipdt}}\right) \\
& -\sum_{\mathrm{i}} \sum_{\mathrm{t}}\left(\mathrm{HCD}_{\mathrm{id}} * \mathrm{ID}_{\mathrm{idt}}\right)-\sum_{\mathrm{i}} \sum_{\mathrm{P}} \sum_{\mathrm{t}}\left(\mathrm{TCPD}_{\mathrm{ipdt}} * \mathrm{PTPD}_{\mathrm{ipdt}}\right)
\end{aligned}
$$

Backorder Level For Retailer $\mathrm{r}$ : (Minimization)

$$
=\sum_{\mathrm{i}} \sum_{\mathrm{c}} \sum_{\mathrm{t}}\left(\mathrm{BCR}_{\mathrm{irct}}\right)
$$

\subsection{Constraints}

$$
\begin{gathered}
\mathrm{FP}_{\text {ipt }} \leq \mathrm{FHCP}_{\text {ipt }} \quad \forall \mathrm{i}, \mathrm{p}, \mathrm{t} \\
\mathrm{ID}_{\text {idt }} \leq \mathrm{PHCP}_{\text {idt }} \quad \forall \mathrm{i}, \mathrm{d}, \mathrm{t} \\
\mathrm{IR}_{\text {irt }} \leq \mathrm{PHCR}_{\text {irt }} \quad \forall \mathrm{i}, \mathrm{r}, \mathrm{t}
\end{gathered}
$$

(4), (5), (6) state that inventory level in each echelon is restricted by inventory capacity.

Since, distributors set due date for delivering items from manufacturer, thus sum of production time in manufacturer and inventory holding time in plants in each period and delivery time items to distributor, should be less than product delivery due date. Thus we have:

$$
\begin{array}{rrr}
\left(\mathrm{PQ}_{\mathrm{ipt}} * \mathrm{TFP}_{\mathrm{i}}\right)+ & \left(\mathrm{TIP}_{\text {ipt }}\right)+\left(\mathrm{TPD}_{\mathrm{pd}} * \mathrm{PTPD}_{\text {ipdt }}\right) \\
\leq \mathrm{DUEM}_{\text {ipdt }} & \forall \mathrm{i}, \mathrm{p}, \mathrm{d}, \mathrm{t} \\
\sum_{\mathrm{i}} \mathrm{PTPD}_{\text {ipdt }} \leq \mathrm{TCM}_{\mathrm{pdt}} & \forall \mathrm{d}, \mathrm{p}, \mathrm{t} \\
\sum_{\mathrm{i}} \mathrm{PTD}_{\text {idrt }} \leq \mathrm{TDR}_{\text {drt }} & \forall \mathrm{d}, \mathrm{r}, \mathrm{t}
\end{array}
$$

(8), (9), mean that the amount of product $\mathrm{i}$ to be transported among echelons is limited by transportation capacity.

$$
\mathrm{ID}_{\text {idt }}=\mathrm{ID}_{\text {idt }-1}+\sum_{\mathrm{p}} \mathrm{PTPD}_{\text {ipdt }}-\sum_{\mathrm{r}} \mathrm{PTD}_{\text {idrt }} \quad \forall \mathrm{i}, \mathrm{d}, \mathrm{t}
$$

(10) is balance equation for DCs; the amount of products that enter to DC $\mathrm{d}$ must be equal to the amount of products that leave from and stored at this DC.

Inventory of product $i$ in plant $p$ in period $t$ is equal to inventory of that product in previous period plus production quantity of product $i$ in plant $p$ in period $t$ minus amount of product $i$ transported from plant $p$ to DCs in period $t$. As shown by (11):

$$
\mathrm{FP}_{\text {ipt }}=\mathrm{FP}_{\text {ipt-1 }}+\mathrm{PQ}_{\text {ipt }}-\sum_{\mathrm{d}} \mathrm{PTPD}_{\text {ipdt }} \quad \forall \mathrm{i}, \mathrm{p}, \mathrm{t}
$$

Backorder level of product $i$ incurred by retailer $r$ in period $t$ equals to backorder level of that product in previous period plus total demand of the product by retailer $r$ in that period. This is shown by (12). 


$$
\sum_{\mathrm{c}} \mathrm{BCR}_{\mathrm{irct}}=\sum_{\mathrm{c}} \mathrm{BCR}_{\mathrm{irc}(\mathrm{t}-1)}+\sum_{\mathrm{c}} \mathrm{CD}_{\mathrm{irct}}-\sum_{\mathrm{c}} \mathrm{TRC}_{\mathrm{irct}} \quad \forall \mathrm{i}, \mathrm{r}, \mathrm{t}
$$

And finally, the backorder level at the last period should be zero for fulfilling the customer demand:

$$
\sum_{\mathrm{c}} \mathrm{BCR}_{\mathrm{ircT}}=0 \quad \forall \mathrm{i}, \mathrm{r}
$$

All of variables are continuous and positive.

\section{Methodology}

\subsection{The Proposed Genetic Algorithm}

In this problem we are dealing with a multiple objective possibilistic linear programming model. To solve this problem, we apply a two-step approach. In the first step, the original problem is converted into an equivalent auxiliary crisp multiple objective linear model. In the second step, a fuzzy goal programming approach which is named TH is used. In this method the crisp multi-objective model convert to a single objective model considering decision maker's imprecise aspiration levels for goals.

To solve the problem, we propose a genetic algorithm (PGA) considering constrained model and compare the results with algorithm which is proposed by Haupt and Haupt[7] (HGA). We use continuous genetic algorithm versus binary genetic algorithm, because variables are continuous. For dealing with our constrained model when model's size is large, we propose a genetic algorithm which its solutions are selected from feasible region as far as possible because it is impossible to select all members of population from feasible region. Then we compare obtained results through this method with method which is proposed by Haupt and Haupt [7] named HGA. In HGA method, constraints are added to objective function by using penalty coefficients.

A constrained model can be stated as follows:

$$
\begin{array}{ll}
\operatorname{Min} \mathrm{f}(\mathrm{x}) & \\
g_{j}(x) \leq 0 & j=1, \ldots, J \\
h_{i}(\mathrm{x})=0 & \mathrm{i}=1, \ldots, \mathrm{I}
\end{array}
$$$$
\text { s.t }
$$

In majority of algorithms, for generating initial population random numbers are used for generating initial population. While, in a problem which includes constraints in addition to objective functions, using this random numbers cannot imply that initial population has been selected from a feasible region or has minimum violation. Also, initial population is the base for constructing next populations. In genetic algorithm which is presented here, we consider this problem. Also initial solution is constructed with minimization of violation. We do it, using PSO algorithm which is an evolutionary algorithm similar to 
genetic algorithm but it have operators less than genetic algorithm. Thus, for generating initial population, we minimize below fitness function: Violation= $\sum_{j} \max \left(0, g_{i}\right)+\sum_{i}\left|h_{i}\right|$

Another difference between our proposed genetic algorithm and other algorithms is that in this algorithm fitness function is the same as objective function. The method for mating which has been proposed by Haupt and Haupt[7] is as follows:

The blending method finds ways to combine variable values from the two parents into new variable values in the offspring. A single offspring variable value, $P_{\text {new }}$, comes from a combination of the two corresponding offspring variable values

$P_{n e w}=\beta P_{m n}+(1-\beta) P_{d n}$ Where: $\beta=$ random number on the interval $[0$, $1], P_{m n}=$ nth variable in the mother chromosome, $P_{d n}=$ nth variable in the father chromosome. In our proposed genetic algorithm for mating, $\beta$ change while the violation for new offspring is less than the average violation in initial population. Also for mutation and selecting the member which should be affected by mutation, we continue generating random numbers while interested violation will be occurred, then replace the amount of selected member with the amount of same member in chromosome which has minimum violation.

\subsection{Analysis of Variance}

In addition to achievement level, another characteristic which has been considered to compare performance of HGA and PGA is violation. It has been done by analysis of variance (ANOVA). An independent t-test has been conducted to test the difference between mean of violations. It is assumed that:

M1: violation which was resulted from HGA

M2: violation which was resulted from PGA

Analysis of variance was done using Minitab. Thus following 2 tests of hypothesis were performed.

$$
\left\{\begin{array}{l}
H_{0}: M_{1}=M_{2} \\
H_{1}: M_{1} \geq M_{2}
\end{array}\right.
$$

Amount of obtained p-value for test of hypothesis 1 is 0.045 . Considering, test of hypothesis is performed with 0.95 for confidence level, and p-value for test of hypothesis is less than 0.05 , thus, null hypothesis is rejected. It shows that mean of violation in PGA is less than HGA (P-value $<0.05)$.

\section{Numerical Example}

To demonstrate the practicality of the proposed model, we considered an assumed SC. In our hypothetically constructed SC, there is a manufacturer company consists of multiple plants, multiple DCs, retailers and customers. First, a problem with a small size has been designed and then results have been 
compared with Lingo's results. Both genetic algorithms run 30 times and satisfaction degree for each goal is calculated. Then we set:

$w_{1}$ (Weight of manufacturer) $=0.3, w_{2}$ (Weight of DCs) $=0.3, w_{3}$ (Weight of retailers $)=0.4$. Also, we set $\delta=0.5$ ( $\delta$ is coefficient in TH method)

$\mathrm{i}=3, \mathrm{t}=4, \mathrm{p}=3, \mathrm{~d}=2, \mathrm{r}=3, \mathrm{c}=3$. We generate all of required parameters randomly. For receiving further information about these random numbers, please contact the corresponding author. To survey the results obtained from Lingo8 and genetic algorithm, a problem with small size has been solved and results have been presented in table1. It is concluded that the average difference between PGA and HGA and lingo is $7 \%$ and $10 \%$ respectively. Obviously, difference between results obtained from PGA and HGA are not large; thus, methods can be used in problems with large size. Now, consider a large model and set: $i=6, t=8, p=5$, $d=2, r=3, c=3$. The satisfaction degree of each goal is shown in table 2; as can be seen, the satisfaction degree for goals in PGA algorithm is more than HGA, and it reveals the efficiency of proposed genetic algorithm.

Table 1. Achievement levels obtained by Lingo, HGA, PGA in small size

\begin{tabular}{llll}
\hline $\begin{array}{l}\text { Achievement } \\
\text { Level }(\%)\end{array}$ & Lingo & HGA & PGA \\
\hline$\mu$ profitM & 0.85 & 0.63 & 0.66 \\
$\mu$ DC1profit & 0.94 & 0.75 & 0.80 \\
$\mu$ DC2profit & 0.92 & 0.72 & 0.76 \\
$\mu$ RET1BLG & 0.95 & 0.75 & 0.79 \\
$\mu$ RET2BLG & 0.75 & 0.61 & 0.69 \\
\hline$\mu$ RET3BLG & 0.87 & 0.65 & 0.71 \\
\hline
\end{tabular}

Table 2. Achievement levels obtained by HGA, PGA in large size

\begin{tabular}{lll}
\hline $\begin{array}{l}\text { Achievement } \\
\text { Level }(\%)\end{array}$ & HGA & PGA \\
\hline uprofitM & 0.59 & 0.6 \\
$\mu$ DC1profit & 0.71 & 0.7 \\
$\mu$ DC2profit & 0.68 & 0.69 \\
$\mu$ RET1BLG & 0.72 & 0.74 \\
$\mu$ RET2BLG & 0.6 & 0.62 \\
\hline$\mu$ RET3BLG & 0.67 & 0.69 \\
\hline
\end{tabular}

\section{Conclusions}

Managing operations in today's competitive market place poses significant challenges. Based on the traditional thought there were so many conflicts in the multiple demands on the operational functions that trade-offs were made in achieving excellence in one or more of these dimensions. 
This paper tackled with integrated inventory-production-distribution planning problem in SC system. A multi-objective linear programming model has been developed in this concern. Decision maker's imprecise aspiration levels for the goals have been incorporated into the model using fuzzy goal programming approach. Computational experiments have been provided from a case problem. A genetic algorithm has been proposed to solve constrained problem and results have been compared to genetic algorithm suggested by Haupt and Haupt(2004). While, in solving problems with constraints there is no guarantee that initial population is feasible or has minimum violation. Proposed Genetic Algorithm, using PSO algorithm, tries to construct initial solution with minimum violation. Also a new mating method has been proposed in our genetic algorithm. In addition we don't use penalty function as fitness function. Numerical results obtained, showed the efficiency of proposed algorithm rather than algorithm used by Haupt and Haupt[7]. The paper contributes to literature in designing a multiple objective linear model for integrated inventory-production-distribution planning which is close to real world supply chain and using fuzzy goal programming, also proposing a new genetic algorithm. Analysis of variance has been used to compare mean of violation in HGA and PGA. It is resulted that violation in PGA is less than HGA. Thus, PGA is closer than HGA to feasible solution.

\section{References}

1. Abbasbandy, S., Asady, B.: Ranking of fuzzy numbers by sign distance. Inform. Sci. 176, 2405-2416 (2006)

2. Aliev, R.A., Fazlollahi, B., Guirimov, B.G., Aliev, R.R.: Fuzzy-genetic approach to aggregate production -distribution planning in supply chain management. Information Sciences 177, 4241-4255 (2007)

3. Chen, S.-H.: Computational intelligence in economics and finance: carrying on the legacy of Herbert Simon. Inform. Sci. 170(1), 121-131 (2005)

4. Chen, S.-P., Chang, P.C.: A mathematical programming approach to supply chain models with fuzzy parameters. Eng., Optimiz. 38(6), 647-669 (2006)

5. Gao, M., Zhou, M.C., Tang, Y.: Intelligent decision making in disassembly process based on fuzzy reasoning Petri nets. IEEE Trans. Syst. Man. Cyb. B: Cyb. 34(5), 2029-2084 (2004)

6. Gottwald, S.: Mathematical fuzzy logic as a tool for the treatment of vague information. Inform. Sci. 172(1-2), 41-71 (2005)

7. Haupt, R.L., Haupt, S.E.: Practical Genetic Algorithm, 2nd edn. John Willey and Sons, Inc., Hoboken (2004)

8. Liang, T.-F.: Distribution planning decisions using interactive fuzzy multi-objective linear programming. Fuzzy Sets Syst. 157(10), 1303-1316 (2006)

9. Nozick, L.K., urnquist, M.A.: Inventory, Transportation, Service quality and the location of distribution centers. European Journal of Operational Research 129, 362-371 (2001)

10. Selim, H., Araz, C., Ozkarahan, I.: Collaborative production-distribution planning in supply chain: A fuzzy goal programming approach. Transportation Research Part E (2007)

11. Sheen, J.N.: Fuzzy financial profitability analyses of demand side management alternatives from participant perspective. Inform. Sci. 169(3-4), 329-364 (2005) 
12. Tasan, A.S.: A Two Step Approach for the Integrated Production and Distribution Planning of a Supply Chain, pp. 883-888. Springer, Heidelberg (2006)

13. Torabi, S.A., Hassini, E.: An interactive possibilistic programming approach for multiple objective supply chain master planning. Fuzzy Sets and Systems 159, 193-214 (2008)

14. Zadroznya, S., Kacprzyk, J.: Computing with words for text processing: an approach to the text categorization. Inform. Sci. 176(4), 415-437 (2006) 